\title{
Potential effects of COVID-19 on reproductive systems and fertility; assisted reproductive technology guidelines and considerations: a review
}

\author{
WY Lee, Alex Mok, Jacqueline PW Chung *
}

\begin{abstract}
A B S T R A C T
Severe acute respiratory syndrome coronavirus 2 (SARS-CoV-2) employs the angiotensin-converting enzyme 2 (ACE2) receptor in the renin-angiotensin system for viral entry. The ACE2 receptor is present in both female and male reproductive systems, and reports of multi-organ involvement have led to uncertainty regarding its effects on the reproductive system and fertility. We review the existing literature regarding the function of ACE2 and the renin-angiotensin system in the female and male reproductive systems to postulate the possible implications of SARS-CoV-2 regarding fertility. Because of the presence of ACE2 in the ovaries, SARS-CoV-2 infection may disrupt ovarian function and hence oocyte quality. Higher expression of ACE2 in the endometrium with age and during the secretory phase raises concern about increased susceptibility to infection during periods of high ACE2 expression. The possibility of vertical transmission and the presence of ACE2 in the placenta and during pregnancy are also discussed. The presence of SARS-CoV-2 RNA in semen is controversial, but impaired semen quality has been found in men with moderate coronavirus disease 2019 infection.
\end{abstract}

This article was published on $15 \mathrm{Apr}$ 2021 at www.hkmj.org.
Evidence of orchitis and hormonal changes seen in male coronavirus disease 2019 infection may lead to infertility. The implications of these effects on assisted reproductive technology (ART) outcomes are also explored. The ART guidelines from different fertility societies for the management of patients treated with ART are provided. The importance of prioritising 'time-sensitive' patients for ART, counselling patients about the uncertainty and risks of ART, and pregnancy during the pandemic is discussed. Recommendations are also provided for infection control and safe regulation of ART centres and laboratories.

\begin{tabular}{l} 
Hong Kong Med J 2021;27:118-26 \\
\hline https://doi.org/10.12809/hkmj209078 \\
${ }^{1}$ WY Lee, MB, ChB \\
${ }^{1}$ A Mok, MB, ChB \\
${ }^{2}$ JPW Chung *, FHKCOG, FHKAM (Obstetrics and Gynaecology) \\
${ }^{1}$ Faculty of Medicine, The Chinese University of Hong Kong, Hong Kong \\
${ }^{2}$ Department of Obstetrics and Gynaecology, The Chinese University of \\
Hong Kong, Hong Kong \\
* Corresponding author: jacquelinechung@cuhk.edu.hk
\end{tabular}

Hong Kong Med J 2021;27:118-26

${ }_{1}^{1}$ WY Lee, MB, ChB

${ }^{1} \mathrm{~A}$ Mok, $\mathrm{MB}, \mathrm{ChB}$

Faculty of Medicine, The Chinese University of Hong Kong, Hong Kong Department of Obstetrics and Gynaecology, The Chinese University of

* Corresponding author: jacquelinechung@cuhk.edu.hk

\section{Introduction}

Coronavirus disease 2019 (COVID-19) is a serious respiratory disease caused by severe acute respiratory syndrome coronavirus 2 (SARS-CoV-2) infection. The SARS-CoV-2 employs the angiotensinconverting enzyme 2 (ACE2) receptor in the reninangiotensin system (RAS) for viral entry. ${ }^{1}$ The ACE2 receptor is present in the reproductive system, and reports of multi-organ involvement have led to uncertainty regarding COVID-19's effects on the reproductive system and fertility. ${ }^{2}$ We reviewed the existing literature regarding the function of ACE2 and RAS in the reproductive system. Our aim was to postulate and understand the effects of SARS-CoV-2 infection on fertility and assisted reproductive technology (ART) outcomes through RAS, so as to prompt further quantitative research. We also discuss guidelines on the management of patients treated with ART and safe regulation of ART centres/ laboratories to improve infection control during the pandemic.

\section{Relationships between severe acute respiratory syndrome coronavirus, angiotensin- converting enzyme 2 receptor, and renin-angiotensin system}

The SARS-CoV-2 virus enters the body via binding to ACE2 expressed on target host cells. ${ }^{1}$ The spike protein of SARS-CoV-2 attaches to this receptor, similarly to SARS-CoV-1, to facilitate endocytosis and cellular infection. ${ }^{1}$ The Figure illustrates the role of ACE2 in RAS. ${ }^{1,3}$

The angiotensin II (Ang II) and Ang-(1-7) hormones have opposing effects. Whereas Ang II is pro-inflammatory, pro-fibrotic, and pro-apoptotic with tissue remodelling properties, Ang-(1-7) is anti-inflammatory and anti-fibrotic. ${ }^{3}$ In other words, ACE1 and ACE2 counteract each other, and their roles are essential in balancing RAS.

Infection with SARS-CoV-2 causes reduced ACE2 activity and downregulation. This increases 
circulating Ang II in patients with SARS-CoV-2 infection. ${ }^{1,4,5}$ This explains the inflammatory and fibrotic effects seen in COVID-19 lung injury. ${ }^{4,5}$

There are increasing reports of multi-organ involvement, with SARS-CoV-2 found in blood, stools, urine, and saliva.,3,6 This suggests that ACE2 in different organ systems may contribute to the pathophysiology of COVID-19 dissemination through viraemia. ${ }^{1-3}$ As ACE2 is also present in the testes and female reproductive system, it is speculated that the reproductive system may also be affected by SARS-CoV-2.7,8 We analysed the local RAS and its function in the reproductive system to postulate how COVID-19 may affect female and male steroidogenesis, germ cells, and reproductive health. ${ }^{8,9}$

\section{Influence of coronavirus disease 2019 on the female reproductive system}

\section{Ovarian and follicular development}

Although ACE2 is ubiquitous in the female reproductive system, it is found mostly in the ovaries. ${ }^{8-10}$ All other components of RAS are also found in the ovaries, making them potential targets for damage by SARS-CoV-2..$^{8-10}$

Angiotensin II, found predominantly in granulosa cells, regulates follicular development, oocyte maturation, and ovulation. ${ }^{8,9}$ It is involved in sex hormone secretion, follicular atresia, and ovarian and corpus luteum angiogenesis. ${ }^{8,10}$ Angiotensin-(1-7), presenting in theca-interstitial cells, is involved in steroidogenesis, oocyte meiosis resumption, follicular development, atresia, and enhancing ovulation. ${ }^{8,9}$ The ACE2, Ang-(1-7), and Mas-receptor are found in all stages of follicular development, and studies in rats demonstrated that their expression was altered by gonadotropin,
2019 冠狀病毒病對生殖系統和生育力的潛在 影響、輔助生殖技術的準則和注意事項的回顧 李詠茹、莫浩平、鍾佩樺

2019 冠狀病毒病是由 SARS-CoV-2 病毒引發的全球大瘟疫。 SARS-CoV-2是經過腎素-血管緊張素系統 (RAS ) 的血管緊張素轉化 酶2（ACE2）受體進入人類身體。現時已有證明SARS-CoV-2能影響 身體不同器官和引起併發症。由於ACE2會在男性和女性生殖系統裏 出現, 有關SARS-CoV2會否影響生殖系統以及生育能力的問題近年備 受關注。我們分析RAS和ACE2在生殖系統的功能、假設SARS-CoV-2 或會影響生育能力、並了解SARS-CoV-2 對輔助生殖技術（ART）的 影響。比較世界不同ART機構治療病人的指南, 分析在疫情下怎樣為 ART病人提供最安全的治療。本文也談論如何改善ART中心及實驗室 運作, 減低感染病毒的風險。在疫情反覆的情況下, 制定ART治療病 人的優先次序, 以及向病人解釋SARS-CoV-2對ART及懷孕帶來的不 明朗因素及風險是最重要的。 implicating the pathway's potential role in fertility. ${ }^{8,9}$ Furthermore, Ang-(1-7) levels in follicular fluid collected during ovarian stimulation for in vitro fertilisation positively correlate with the proportion of mature oocytes. ${ }^{11}$ Combined with animal studies proving a causal relationship between Ang-(1-7) and oocyte maturation, the evidence indicates that Ang-(1-7) may be a human oocyte maturation factor. ${ }^{11}$

The downregulation of ACE2 by SARS-CoV-2 may cause alterations in normal ovarian physiology, such as follicular development and oocyte maturation, impacting oocyte quality and fertility. Oxidative stress is also increased by Ang II as it exerts pro-inflammatory effects. ${ }^{9}$ This may be detrimental to reproductive ability. Further investigations ought

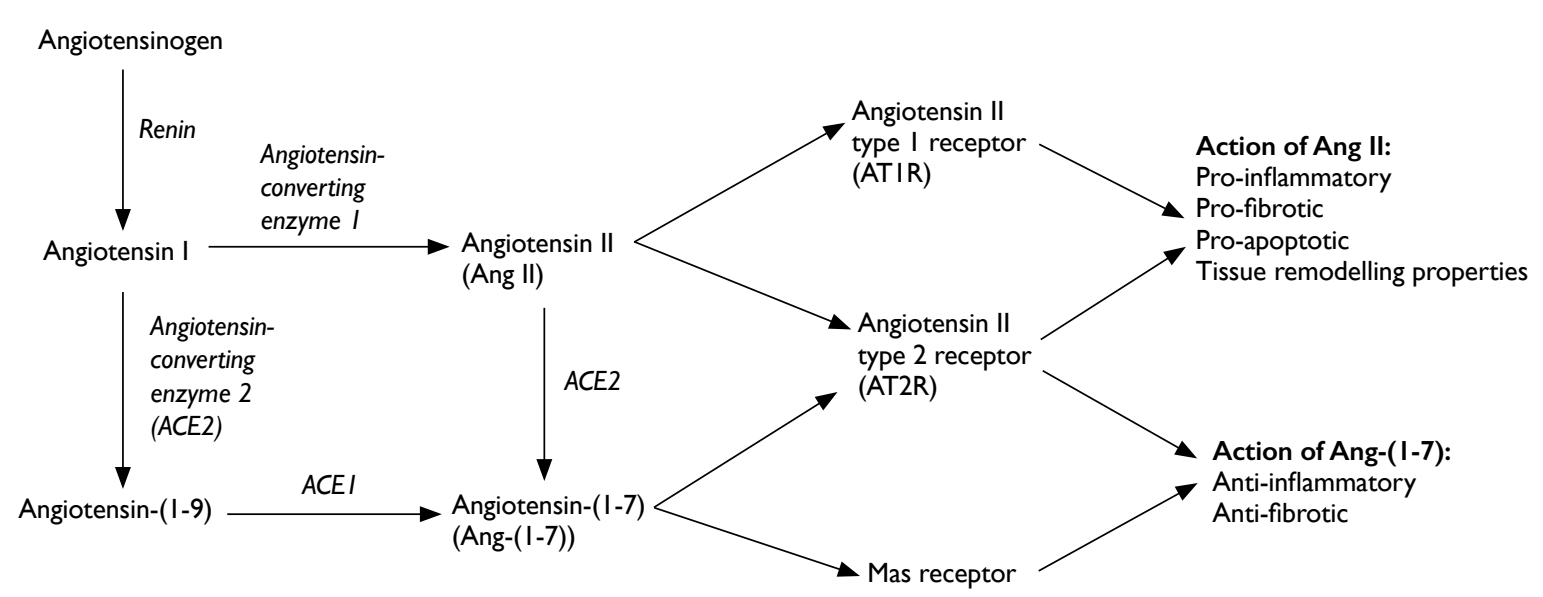

FIG. Role of angiotensin-converting enzyme 2 in the renin angiotensin system ${ }^{1,3}$ 
to be done to demonstrate whether increased Ang II/Ang II type 1 receptor (AT1R) signalling in SARS-CoV-2 cases affects ovarian physiology and fertility.

\section{Uterus and fallopian tubes}

The RAS is present in theuterus, mostly confined to the epithelial and stromal cells of the endometrium. . $^{8,10,12}$ Thus, if COVID-19 damages endometrial epithelial cells, it may affect early embryo implantation. ${ }^{13}$ Little research has been done to analyse RAS function in the uterus, but the expression of RAS components fluctuates during the cycle. ${ }^{10}$ The ACE2, Ang-(1-7), and Mas receptor expression are higher in the secretory than the proliferative phase, whereas Ang II and AT1R expression are higher in the proliferative than the secretory phase. ${ }^{8,10,12}$ This raises concern about whether the endometrium is more susceptible to SARS-CoV-2 during the secretory phase. Nevertheless, a study by Henarejos-Castillo et $\mathrm{al}^{14}$ revealed low overall endometrial susceptibility to SARS-CoV-2. They also reported a positive correlation between age and SARS-CoV-2-related gene expression (ACE2), suggesting increased susceptibility to endometrial infection in older women. ${ }^{14,15}$

A normal level of Ang II expression is crucial to maintaining regular menstrual cycles and endometrial activity, as it facilitates regeneration of blood vessels and the endometrium and initiates menstruation. ${ }^{8}$ Endometrial and myometrial activities including endometrial regeneration, proliferation, fibrosis, and stromal proliferation are regulated by the intricate balance of Ang II and Ang-(1-7) in the uterus, ie, stimulated by Ang II and inhibited by Ang-(1-7). ${ }^{8}$ Infection of the uterus with SARS-CoV-2 may severely disrupt such balance. Disruption of Ang II levels has been found to be related to dysfunctional uterine bleeding associated with hyperplastic endometrium. ${ }^{8}$ Whether this has any correlation to altered blood flow and increased risk of miscarriage is unknown and requires further quantitative research.

In the fallopian tubes, Ang II has been found in the endothelium and stroma. ${ }^{10}$ Both AT1R and AT2R are present in the epithelium. ${ }^{8,10,12}$ Similarly to Ang II/ AT1R expression fluctuation in the uterus, AT1R expression also changes throughout the cycle (ie, higher in the proliferative and lower in the secretory phase). ${ }^{12}$ The function of Ang II remains unclear, but one study reported that it stimulates the ciliary beat frequency in epithelial cells. ${ }^{8,10,12}$

\section{Placenta and pregnancy}

Studies regarding vertical transmission are controversial, and there is insufficient evidence to confirm transplacental COVID-19 infection. One study detected SARS-CoV-2 in the placental and fetal membranes, but the infants tested negative in the first 5 days of life. ${ }^{16}$ Possible contamination sources include maternal blood, vaginal secretions, and amniotic fluid. ${ }^{16}$ Nevertheless, the risk of placental/ amniotic sac COVID-19 infection still cannot be ruled out, warranting further research.

Expression of ACE2 is higher in the placenta than in the lungs, ${ }^{8}$ further substantiating the risk of placental SARS-CoV-2 infection. Low placental ACE2 and Ang-(1-7) have been reported to be associated with intrauterine growth restriction, an outcome that has also been seen in pregnant patients with COVID-19. ${ }^{8}$ This signifies that placental COVID-19 infection may have severe implications for pregnancy outcomes.

Local RAS expression has been identified in the placenta and cell lines as early as 6 weeks of gestation, but its function remains ambiguous. ${ }^{10}$ One study reported possible RAS involvement in trophoblast invasion and angiogenesis and suggested that local RAS alteration may contribute to abnormal uteroplacental perfusion, leading to pre-eclampsia. ${ }^{10}$

The maternal decidua and pericytes of endometrial spiral arteries also contain Ang II. Angiotensin II type 1 receptor is found in maternal decidua, cytotrophoblasts, syncytiotrophoblasts, and fetal capillaries, ${ }^{10}$ and Ang-(1-7) and ACE2 are localised in syncytiotrophoblasts, cytotrophoblasts, and the endothelium and vascular smooth muscle of primary and secondary villi. ${ }^{8,10}$ Angiotensinconverting enzyme 2 is also localised in invading and intravascular trophoblasts and in decidual cells of maternal stroma. ${ }^{8}$ In the umbilical cord, ACE2 is localised in smooth muscles and the vascular endothelium. $^{8}$ All of these serve as potential SARS-CoV-2 entry points to the placenta.

In addition, RAS expression fluctuates throughout pregnancy. ${ }^{10}$ Whereas AT1R expression increases during gestation and peaks at the end, ACE2 peaks early in gestation. ${ }^{8,10}$ Whether this causes increased susceptibility to placental SARS-CoV-2 infection during early gestation is unknown. The expression of ACE2 also differs in location throughout pregnancy: it appears in the primary and secondary decidual zones, the luminal zone, and the glandular epithelium during early gestation and in the labyrinth placenta and the epithelium of the amniotic and yolk sac during late gestation. ${ }^{8}$

\section{Implications on outcomes of assisted reproductive technology}

Whereas COVID-19 has not yet been reported to damage female fertility, its potential detrimental effects cannot be ignored. If patients who recover from COVID-19 undergo ART, it is unknown whether their oocyte quality, quantity, and other parameters will be affected, nor is the duration of abnormality. Future research should be conducted to assess these parameters. 


\section{Influence of coronavirus disease 2019 on the male reproductive system}

\section{Angiotensin-converting enzyme 2 receptor in the male reproductive system}

Some parts of the testis have been found to contain ACE2 (the spermatogonia, Leydig cells, and Sertoli cells), rendering them potential SARS-CoV-2 targets., ${ }^{9,17}$ The Leydig cells, Sertoli cells, and seminiferous tubules also contain Ang-(1-7) and Mas receptor. ${ }^{9,17}$

Infertile men with severely impaired spermatogenesis have lower ACE2, Ang-(1-7), and Mas receptor levels compared with fertile men. ${ }^{9}$ Men with non-obstructive azoospermia were found to have absence of Ang-(1-7) and Mas receptor in the seminiferous tubules. ${ }^{17}$ As Leydig cells are responsible for steroidogenesis and secretion, particularly testosterone, ACE2, Ang-(1-7) and Mas expression in Leydig cells strongly suggests their potential roles in the regulation of steroidogenesis and secretion, spermatogenesis, and hence their influence on male fertility.,17 Therefore, ACE2 downregulation in COVID-19 may impair spermatogenesis and male fertility. Nevertheless, ACE2 knockout mice demonstrated no reduction in fertility, suggesting the possibility of other rescue mechanisms that may compensate for ACE2 loss.,

Angiotensin II in the testes inhibits Leydig cells and testosterone production and regulates anion and fluid secretion from the epididymis. ${ }^{18}$ The increase of Ang II induced by COVID-19 may hypothetically affect these functions.

\section{Positive severe acute respiratory syndrome coronavirus 2 in semen}

Presence of SARS-CoV-2 RNA in semen has been controversial among studies. A cross-sectional observational study by Pan et $\mathrm{al}^{19}$ was unable to identify SARS-CoV-2 in semen samples among 34 confirmed cases 1 month after diagnosis. Another study by $\mathrm{Li}$ et $\mathrm{al}^{20}$ revealed six cases that were positive for SARS-CoV-2 in semen: four during the acute infection and two during the recovery phase. This raises concern about sexual transmission during the acute and particularly the recovery phase of infection. This may have negative implications on fertility, assisted reproduction, vertical transmission, and fetal development. Abstinence and condoms should be used to reduce the potential risk of sexual transmission until more evidence is available. ${ }^{20}$

\section{Orchitis in coronavirus infection}

Multiple studies have reported a high risk of male patients with COVID-19 developing orchitis-like symptoms, suggesting viral orchitis. ${ }^{17}$ A histological study of 12 testes of deceased patients with
COVID-19 revealed characteristics of viral orchitis, lymphocytic infiltration, seminiferous tubular injury, reduced numbers of Leydig cells, vascular congestion, and extensive germ cell destruction. ${ }^{21}$ As COVID-19 is associated with coagulopathy, the orchitis could have resulted from vasculitis. ${ }^{22}$

The possibility of orchitis leading to infertility as a complication of infection with coronaviruses such as SARS-CoV-1 is widely accepted. ${ }^{23,24}$ Similar to the case in COVID-19, pathology revealed focal testicular atrophy, germ cell destruction with decreased number of spermatozoa, and inflammatory cell infiltrates. ${ }^{17,23,24}$ Interestingly, SARS-CoV-1 was not identified in the testis; instead, high immunoglobulin G precipitation was detected in the seminiferous epithelium, suggesting that an immune-mediated response was causing the testicular damage, rather than direct testicular infection. ${ }^{17,23,24}$ Male patients with COVID-19 and high immunoglobulin $\mathrm{G}$ titre might also have adverse reproductive effects, possibly caused by anti-sperm antibodies such as antiphospholipid antibodies, which interfere with fertilisation. ${ }^{25}$

Inflammatory infiltration may disrupt spermatogenesis, impede steroidogenesis, and destroy cells in seminiferous tubules. ${ }^{26}$ Moreover, SAR-CoV-2 induces oxidative stress via inflammatory responses, which might disrupt the process of spermiogenesis and lead to spermatozoa having poorly remodelled chromatin. ${ }^{27}$ Cytokine release activates a secondary autoimmune response and production of antibodies within the seminiferous tubules, leading to autoimmune orchitis and the presence of antibodies in semen. ${ }^{25,26}$ The cytokine response may also suppress the hypothalamicpituitary-gonadal axis, leading to reduction of testosterone and sperm production. ${ }^{25}$ This is consistent with studies that have revealed reduced serum testosterone in patients with COVID-19.25 Semen analysis and follow-up of patients with orchitis during COVID-19 infection should be conducted to evaluate their reproductive functioning.

\section{Hormonal changes in patients with coronavirus disease 2019: signs of hypogonadism}

Multiple studies have revealed significant increases in serum luteinising hormone (LH) and prolactin levels among male patients with COVID-19. ${ }^{28,29} \mathrm{~A}$ significant decrease in testosterone to $\mathrm{LH}$ ratio and follicle-stimulating hormone to $\mathrm{LH}$ ratio were also reported. ${ }^{29}$ It is postulated that the $\mathrm{LH}$ increase in COVID-19 resulted from the early stage of impaired testosterone production and was caused by reduction of Leydig cells. This could have caused negative feedback that stimulated Leydig cells to temporarily increase testosterone production. ${ }^{28}$ There may be a risk of clinical hypogonadism as 
the disease progresses..$^{28}$ It is therefore important to perform follow-up with post-recovery patients for at least 3 to 6 months, with serum LH and testosteroneto- $\mathrm{LH}$ ratio serving as clinical indicators of primary hypogonadism. ${ }^{29}$

\section{Implications on the outcomes of assisted reproductive technology}

Infection and viral-mediated immune response to SARS-CoV-2 may disrupt steroidogenesis and spermatogenesis and destroy cells of the seminiferous tubules. ${ }^{17,26}$ A systematic review on semen analysis by Khalili et $\mathrm{al}^{30}$ revealed significantly impaired semen quality in patients with moderate active COVID-19 infection compared with mild active infection and a control group. Semen samples of patients with moderate SARS-CoV-2 infection were shown to have significantly lower sperm concentration $(\mathrm{P}<0.05)$, lower total number of sperm per ejaculation, lower total number of motile sperm, and lower total number of progressively motile sperm than normal patients. ${ }^{30}$ In combination with the risk of sexual transmission, the consideration of deferring conception in recovered patients until more evidence is available should be taken seriously. Sperm donation/cryopreservation of active/recovered COVID-19 patients should be avoided, as many viruses remain viable and infectious when cryopreserved. ${ }^{31}$

\section{Assisted reproductive technology recommendations for patients with coronavirus disease 2019 and the general public during the pandemic}

\section{Coronavirus disease 2019 infection and possible outcomes of assisted reproductive technology}

In consideration of the lack of legitimate evidence and the fact that the available data are mostly derived from studies with small sample sizes, the risk of serious implications of COVID-19 on fertility cannot be ruled out. Furthermore, fever is common in SARS-CoV-2 infection. In female patients who are undergoing ovarian stimulation for in vitro fertilisation, fever negatively affects follicular development and ovarian oestradiol production. ${ }^{32}$ In male patients, fever transiently impairs spermatogenesis and sperm parameters (count, motility, and DNA integrity) for 50 to 70 days. ${ }^{17,33}$ Male patients with SAR-CoV-2 may also develop cytokine storm syndrome, which may disrupt testicular function..$^{21}$ Therefore, patients treated with ART, gamete donors, and gestation carriers with acute/recovered SARS-CoV-2 infection should avoid participation in any fertility programmes until more research is conducted. ${ }^{34}$

\section{Guidelines on assisted reproductive technology procedures}

Infertility is a time-sensitive disease: the longer it is left untreated, the lower the patient's chances of becoming a biological parent. Previously, fertility societies recommended cessation of all reproductive care except urgent cases. ${ }^{35}$ However, as countries around the world begin to successfully mitigate the spread of COVID-19, a new joint statement was released on 29 May 2020 by the American Society for Reproductive Medicine, the European Society of Human Reproduction and Embryology (ESHRE), and the International Federation of Fertility Societies. The statement sanctioned gradual resumption of full reproductive care in areas where COVID-19 has been well controlled. ${ }^{35}$ Recognition of the importance of fertility care provides relief for infertile patients whose reproductive time is running out.

Risk assessment should take place within ART centres to access practices before restarting services. ${ }^{36}$ Staff should closely monitor the local COVID-19 situation for updated epidemiological data and changes to governmental regulations. ${ }^{36}$ The ESHRE/local triage questionnaires, and if feasible, COVID-19 testing should be done in all patients and partners before starting ART. ${ }^{37}$ In Hong Kong, testing is also performed before ovarian retrieval and embryo transfer, as test results are only valid for 72 hours under local guidelines.

Specific protocols should be enforced regarding screening and management of patients treated with ART during the pandemic. ${ }^{38}$ Table 1 provides such guidelines by different fertility societies..$^{38-43}$ The ESHRE guideline is used as a reference point. Other societies' recommendations that are the same as those of ESHRE are omitted, ie, only extra information is added for other societies. Because of the ever-changing nature of this pandemic and the variability of cases between countries, there may be future changes to ART regulations. The most updated country-specific regulations should be followed.

There is an increased risk of lung and kidney complications if patients with COVID-19 develop ovarian hyperstimulation syndrome during ovarian stimulation. ${ }^{44}$ An individualised approach should be adopted. Anti-Müllerian hormone and antral follicle count should be used to assess ovarian reserve and guide the dosage of gonadotrophins. The gonadotrophin-releasing hormone $(\mathrm{GnRH})$ antagonist protocol (with $\mathrm{GnRH}$ agonist triggering oocyte maturation and elective cryopreservation of embryos) is extremely effective at minimising the risk of ovarian hyperstimulation syndrome. ${ }^{43}$ Moreover, the risk of coagulopathy in COVID-19 may augment the risk of thromboembolic complications during ovarian stimulation. ${ }^{45}$ Other than using $\mathrm{GnRH}$ 
TABLE I. Guidelines for screening and management of patients treated with assisted reproductive technology

\begin{tabular}{|c|c|c|}
\hline & Already started cycles & Planned cycles/pregnancy \\
\hline $\begin{array}{l}\text { The European Society of Human } \\
\text { Reproduction and Embryology } \\
\text { (updated } 14 \text { Oct 2020) }\end{array}$ & $\begin{array}{l}\text { - Follow standard procedures unless changes occur } \\
\text { between ovulation trigger and oocyte retrieval. } \\
\text { - If positive triage, run SARS-CoV-2 IgM/lgG and/or } \\
\text { reverse transcription polymerase chain reaction test. } \\
\text { Decide to continue/defer based on result. } \\
\text { - If test is positive before ovulation trigger/embryo } \\
\text { thawing, defer treatment. } \\
\text { - If a potentially positive patient must continue } \\
\text { treatment (oncological patient or high-risk OHSS), } \\
\text { the following should be implemented: } \\
\text { o Filtering facepiece with } 2 \text { or } 3 \text { masks } \\
\text { o Gowning } \\
\text { o COVID-19 specific disinfection of all areas after } \\
\text { procedure } \\
\text { - If patient/partner symptomatic after oocyte retrieval } \\
\text { or suspected of/positive during embryo culture, } \\
\text { adopt freeze-all policy. } \\
\text { - ET only for low-risk/asymptomatic cases. }\end{array}$ & $\begin{array}{l}\text { - All patients can choose to continue/postpone } \\
\text { ART. }\end{array}$ \\
\hline
\end{tabular}

Additional recommendations not mentioned in ESHRE:

The American Society for

Reproductive Medicine ${ }^{39}$ (8 Sep 2020)
For donor/gestational carrier: defer oocyte retrieval and ET if positive/symptomatic during stimulation/ before ET.

- Serology testing for SARS-CoV-2 in all patients undergoing surgery.

The Association of Reproductive and Clinical Scientists and British Fertility Society $^{40}$ (6 May 2020)

Fertility Society of Australia ${ }^{41,42}$ (24 Mar 2020)

The Italian Society of Fertility and Sterility and Reproductive Medicine ${ }^{43}$ (Jun 2020)
For patient/donor suspected of/positive after ovulatory trigger, risk assessment should be done to assess whether to continue/postpone oocyte retrieval.

High-risk patients should consider cycle cancellation, oocyte and embryo freezing, and deferral of ET until complete recovery.
- Do screening questionnaire \pm antigen testing

- Positive patients/donors defer ART until completely recovered and not infectious.

Discuss appropriateness of postponing treatment. Any medical conditions warranting continuation of treatment?

- Defer in high-risk patients with pre-existing medical history such as renal, liver, or heart disease, diabetes mellitus, hypertension, or immunosuppressive conditions.

- Prioritise urgent patients to start ART. Defer treatment for young patients undergoing ovulation induction for timed sexual intercourse and intrauterine insemination.

Abbreviations: ART = assisted reproductive technology; COVID-19 = coronavirus disease 2019; ESHRE = European Society of Human Reproduction and Embryology; ET = embryo transfer; Ig = immunoglobulin; OHSS = ovarian hyperstimulation syndrome; SARS-CoV-2 = severe acute respiratory syndrome coronavirus 2

agonist in high responders/patients with COVID-19, suggested solutions to reduce thromboembolic risk include segmenting the in vitro fertilisation cycle and administering prophylactic low-molecularweight heparin. ${ }^{45}$

\section{Infection control in assisted reproductive technology centres and laboratories}

Table 2 lists recommendations for infection control in ART centres and laboratories to help reduce the spread of COVID-19. ${ }^{36,38,43,44,46-49}$

As SARS-CoV-2 can be present in semen, strict protective protocols should be implemented in specimen handling to avoid spillage/exposure..$^{50}$ If the operator becomes infected, cryopreserved semen samples handled by the operator should be tested via polymerase chain reaction. ${ }^{48}$ The viral titre of COVID-19-positive semen should be kept at the lowest possible level. ${ }^{51}$ For gametes/embryos, repeated washing should be done to dilute out any viral contaminants. ${ }^{51}$

\section{Identification of 'time-sensitive' patients for assisted reproductive technology}

With the gradual resumption of reproductive services, it is crucial to identify and prioritise patients who have a low prognosis of ART success and whose fertility potential deteriorates rapidly. ${ }^{43,47}$ Stratifying patients according to Poseidon groups, patients in Poseidon groups 2 and 4 (advanced maternal age with normal/reduced ovarian reserve) should be prioritised, followed by group 3 (age $<35$ years but with reduced ovarian reserve). ${ }^{47}$ In male patients who undergo medical treatment to improve sperm quality and quantity, their 'fertility window' is short and transient. Sperm analysis and banking should be done as soon as possible to increase their prospects of biological parenthood. 
TABLE 2. Infection control recommendation for assisted reproductive technology centres and laboratories

\begin{tabular}{|c|c|}
\hline ART centres ${ }^{36,38,43,44,46-48}$ & ART Laboratories ${ }^{36,38,43,44,46-49}$ \\
\hline $\begin{array}{l}\text { - Telehealth (phone/video call): for symptom screenings/ } \\
\text { questionnaires, travel and close contact history, and all medical } \\
\text { consultations where face-to-face meeting is not required. } \\
\text { - Advise male patients to produce semen samples at home } \\
\text { before delivering them to laboratory. } \\
\text { - Screen patients' temperature and symptoms on arrival. } \\
\text { - Limit number of persons simultaneously in waiting rooms, with } \\
\text {-1-m spacing between parties. } \\
\text { - Restrict access to chaperones. Request that patients wait in } \\
\text { their vehicles until their appointment times. } \\
\text { - Use personal protective equipment, eye protection, masks, } \\
\text { gloves, overshoes. Provide alcohol sanitiser. } \\
\text { - Assess air quality control by air filtration system and air } \\
\text { pressurisation, particularly in laboratory. } \\
\text { - All areas regularly sanitised with alcohol-based disinfectant } \\
\text { ( } \geq 75 \% \text { alcohol or } 5 \% \text { chlorine). }\end{array}$ & $\begin{array}{l}\text { - For cryopreservation of suspected/confirmed COVID-19-positive samples, } \\
\text { store in separate high-security straws and/or vapour phase cryostorage } \\
\text { tanks. Do not use Makler chamber/haemocytometer for COVID-19-positive } \\
\text { samples. } \\
\text { - LN used for cryostorage can be contaminated with COVID-19. Use close } \\
\text { system vitrification systems to avoid direct contact of embryos to LN } \\
\text { and incorporate CBS high-security straws/other cryostorage systems. } \\
\text { Alternatively, use sterile LN and vapour storage, UV sterilisation of LN, } \\
\text { or sterile liquid air. For COVID-19 cases, use separate LN cryostorage } \\
\text { systems. } \\
\text { - All areas and equipment disinfected after each procedure. If any patient/ } \\
\text { staff member is positive, implement specific COVID-19 disinfection. } \\
\text { - Arrange staff into shift teams. If a staff member is infected, only one team } \\
\text { has to undergo quarantine. } \\
\text { - Revise emergency plans and arrange external embryologists for substitutes } \\
\text { or refer patients to another ART centre in case all staff are quarantined. } \\
\text { - Train other personnel how to operate/refill cryobanks and handle } \\
\text { cryopreserved specimens in case lab staff is quarantined. } \\
\text { - Minimise contact of laboratory staff with external personnel and patients. } \\
\text { - Avoid transporting cryopreserved specimens between centres. }\end{array}$ \\
\hline
\end{tabular}

Abbreviations: ART = assisted reproductive technology; COVID-19= coronavirus disease 2019; LN = liquid nitrogen

Regarding fertility preservation, patients with cancer and inflammatory and autoimmune diseases should be given priority, as their treatments are gonadotoxic. ${ }^{43,47,48}$ Fertility preservation can only be done during the 'remission window', which is achieved after temporary discontinuation of therapy for 3 to 4 months. ${ }^{47,48}$ If those patients' remission window coincided with the pandemic, they would have to either forego this ART opportunity and start gonadotoxic drugs again, meaning reduced ART success in future attempts as they age, or go without drugs for an extended period of time in the hopes of resuming fertility care. This would cause them to bear the risk of their medical conditions flaring up. ${ }^{48}$ Furthermore, the COVID-19 pandemic should be a novel indication for fertility preservation, especially in Poseidon groups 2 and $4 .{ }^{52}$

\section{Considerations for members of the general public who wish to undergo in vitro fertilisation}

Because of the lack of data and knowledge about SARS-CoV-2, it is imperative to discuss the uncertainties of COVID-19's effects on fertility and ART with patients. Well-documented informed consent should be signed before commencing ART treatment. Patients should understand all the risks involved, including the risk of exposure at the ART clinic during treatment. In addition, it is important to counsel patients about the available options, from postponing to resuming treatment. Balancing should be done between the risks of deferring treatment in patients with low ART prognosis and those of undergoing treatment on fertility and pregnancy. ${ }^{47}$

The unknown effects of COVID-19 on pregnancy outcomes must also be discussed.
Although there is no clear evidence of vertical transmission, it still cannot be ruled out. 2,16,43,46,53,54 Immunosuppression and hormonal fluctuation during pregnancy leave women more vulnerable to respiratory pathogens and severe pneumonia. ${ }^{46}$ Nevertheless, a study revealed no higher susceptibility to COVID-19 in pregnant women than non-pregnant women. ${ }^{36}$ Further, pregnant women with COVID-19 do not have more severe symptoms than non-pregnant women. ${ }^{46,53,55}$

Despite the unclear pathogenesis of COVID-19 in pregnancy, it is associated with more maternal and fetal complications. ${ }^{46}$ These include preterm birth (most common), fetal distress, intrauterine growth restriction, and increase in Caesarean sections. ${ }^{46,54,56,57}$ Miscarriages and neonatal and maternal deaths have been reported, but no evidence has suggested that they are caused directly by COVID-19.46,54,56,57 Pre-existing co-morbidity in pregnant women with COVID-19 is associated with increased severity, higher intensive care unit admission, invasive ventilation, and neonatal unit admission of their newborns. ${ }^{58}$ These data are from women infected during the third trimester, and COVID-19's effects during the first trimester are unknown. ${ }^{46,53,59}$

Patients with infertility face a high amount of stress, from fear of ART failure to uncertainty about the pandemic. ${ }^{43}$ Clinical and psychological support should be provided to advocate for patients' wellbeing and to reduce treatment dropout.

\section{Conclusion}

Coronavirus disease 2019 has affected every part of the world, and it is likely to persist in the coming years. The potential risk of SARS-CoV-2 
infection in the reproductive system and its effects on reproductive parameters and fertility cannot be ignored and warrant further quantitative research.

Shared decisions between doctors and patients should be made regarding fertility care. Patients' autonomy allows them to decide whether to resume or postpone treatment, but it is their doctors' responsibility to counsel them on all the risks and benefits involved. Individualisation of patients' ART treatment is the key to safe practice during this ongoing pandemic.

\section{Author contributions}

Concept or design: All authors.

Acquisition of data: WY Lee, A Mok.

Analysis or interpretation of data: All authors.

Drafting of the manuscript: All authors.

Critical revision of the manuscript for important intellectual content: JPW Chung.

All authors had full access to the data, contributed to the study, approved the final version for publication, and take responsibility for its accuracy and integrity.

\section{Conflicts of interest}

As an editor of the journal, JPW Chung was not involved in the peer review process. Other authors have disclosed no conflicts of interest.

\section{Funding/support}

This research received no specific grant from any funding agency in the public, commercial, or not-for-profit sectors.

\section{References}

1. Sriram K, Insel PA. A hypothesis for pathobiology and treatment of COVID-19: The centrality of ACE1/ACE2 imbalance. Br J Pharmacol 2020;177:4825-4.

2. Li Y, Zhou W, Yang L, You R. Physiological and pathological regulation of ACE2, the SARS-CoV-2 receptor. Pharmacol Res 2020;157:104833.

3. Bourgonje AR, Abdulle AE, Timens W, et al. Angiotensinconverting enzyme 2 (ACE2), SARS-CoV-2 and the pathophysiology of coronavirus disease 2019 (COVID-19). J Pathol 2020;251:228-48.

4. Verdecchia P, Cavallini C, Spanevello A, Angeli F. The pivotal link between ACE2 deficiency and SARS-CoV-2 infection. Eur J Intern Med 2020;76:14-20.

5. Kuba K, Imai Y, Rao S, et al. A crucial role of angiotensin converting enzyme 2 (ACE2) in SARS coronavirusinduced lung injury. Nat Med 2005;11:875-9.

6. Wang W, Xu Y, Gao R, et al. Detection of SARS-CoV-2 in different types of clinical specimens. JAMA 2020;323:18434.

7. Fu J, Zhou B, Zhang L, et al. Expressions and significances of the angiotensin-converting enzyme 2 gene, the receptor of SARS-CoV-2 for COVID-19. Mol Biol Rep 2020;47:438392.

8. Yan J, Li RQ, Wang HR, et al. Potential influence of COVID-19/ACE2 on the female reproductive system. Mol Hum Reprod 2020;26:367-73.

9. Pan PP, Zhan QT, Le F, Zheng YM, Jin F. Angiotensin- converting enzymes play a dominant role in fertility. Int J Mol Sci 2013;14:21071-86.

10. Herr D, Bekes I, Wulff C. Local renin-angiotensin system in the reproductive system. Front Endocrinol (Lausanne) 2013;4:150.

11. Cavallo IK, Dela Cruz C, Oliveira ML, et al. Angiotensin-(1-7) in human follicular fluid correlates with oocyte maturation. Hum Reprod 2017;32:1318-24.

12. Vinson GP, Saridogan E, Puddefoot JR, Djahanbakhch O. Tissue renin-angiotensin systems and reproduction. Hum Reprod 1997;12:651-62.

13. Li R, Yin T, Fang F, et al. Potential risks of SARS-CoV-2 infection on reproductive health. Reprod Biomed Online 2020;41:89-95.

14. Henarejos-Castillo I, Sebastian-Leon P, Devesa-Peiro A, Pellicer A, Diaz-Gimeno P. SARS-CoV-2 infection risk assessment in the endometrium: viral infection-related gene expression across the menstrual cycle. Fertil Steril 2020;114:223-32.

15. Abhari S, Kawwass JF. Endometrial susceptibility to SARS CoV-2: explained by gene expression across the menstrual cycle? Fertil Steril 2020;114:255-6.

16. Penfield CA, Brubaker SG, Limaye MA, et al. Detection of severe acute respiratory syndrome coronavirus in placental and fetal membrane samples. Am J Obstet Gynecol MFM 2020;2:100133.

17. Younis JS, Abassi Z, Skorecki K. Is there an impact of the COVID-19 pandemic on male fertility? The ACE2 connection. Am J Physiol Endocrinol Metab 2020;318:E878-80.

18. Leung PS, Sernia C. The renin-angiotensin system and male reproduction: new functions for old hormones. J Mol Endocrinol 2003;30:263-70.

19. Pan F, Xiao X, Guo J, et al. No evidence of severe acute respiratory syndrome-coronavirus 2 in semen of males recovering from coronavirus disease 2019. Fertil Steril 2020;113:1135-9.

20. Li D, Jin M, Bao P, Zhao W, Zhang S. Clinical characteristics and results of semen tests among men with coronavirus disease 2019. JAMA Netw Open 2020;3:e208292.

21. Singh B, Gornet M, Sims H, Kisanga E, Knight Z, Segars J. Severe acute respiratory syndrome coronavirus 2 (SARS-CoV-2) and its effect on gametogenesis and early pregnancy. Am J Reprod Immunol 2020;84:e13351.

22. Corona G, Baldi E, Isidori AM, et al. SARS-CoV-2 infection, male fertility and sperm cryopreservation: a position statement of the Italian Society of Andrology and Sexual Medicine (SIAMS) (Società Italiana di Andrologia e Medicina della Sessualità). J Endocrinol Invest 2020;43:1153-7.

23. Segars J, Katler Q, McQueen DB, et al. Prior and novel coronaviruses, Coronavirus Disease 2019 (COVID-19), and human reproduction: what is known? Fertil Steril 2020;113:1140-9.

24. Xu J, Qi L, Chi X, et al. Orchitis: a complication of severe acute respiratory syndrome (SARS). Biol Reprod 2006;74:410-6.

25. Huang C, Ji X, Zhou W, et al. Coronavirus: a possible cause of reduced male fertility. Andrology 2021;9:80-7.

26. Paoli D, Pallotti F, Colangelo S, et al. Study of SARS-CoV-2 in semen and urine samples of a volunteer with positive naso-pharyngeal swab. J Endocrinol Invest 2020;43:181922. 
27. Sengupta P, Dutta S. Does SARS-CoV-2 infection cause sperm DNA fragmentation? Possible link with oxidative stress. Eur J Contracept Reprod Health Care 2020;25:4056.

28. Illiano E, Trama F, Costantini E. Could COVID-19 have an impact on male fertility? Andrologia 2020;52:e13654

29. Verma S, Saksena S, Sadri-Ardekani H. ACE2 receptor expression in testes: implications in coronavirus disease 2019 pathogenesis. Biol Reprod 2020;103:449-51.

30. Khalili MA, Leisegang K, Majzoub A, et al. Male fertility and the COVID-19 pandemic: systematic review of the literature. World J Mens Health 2020;38:506-20.

31. Yakass MB, Woodward B. COVID-19: should we continue to cryopreserve sperm during the pandemic? Reprod Biomed Online 2020;40:905.

32. Awwad J, Ghazeeri G, Toth T, Hannoun A, Abdallah MA Farra C. Fever in women may interfere with follicular development during controlled ovarian stimulation. Int Hyperthermia 2012;28:742-6.

33. Sergerie M, Mieusset R, Croute F, Daudin M, Bujan L. High risk of temporary alteration of semen parameters after recent acute febrile illness. Fertil Steril 2007;88:970.e1-7.

34. Cardona Maya WD, Du Plessis SS, Velilla PA. SARS-CoV-2 and the testis: similarity with other viruses and routes of infection. Reprod Biomed Online 2020;40:763-4.

35. Veiga A, Gianaroli L, Ory S, Horton M, Feinberg E, Penzias A. Assisted reproduction and COVID-19: a joint statement of ASRM, ESHRE and IFFS. Hum Reprod Open 2020;2020:hoaa033.

36. American Society for Reproductive Medicine. Patient management and clinical recommendations during the coronavirus (COVID-19) pandemic. Update \#3 (April 24, 2020 through May 11, 2020). Available from: https:// www.asrm.org/globalassets/asrm/asrm-content/newsand-publications/covid-19/covidtaskforceupdate3.pdf. Accessed 11 May 2020.

37. European Society of Human Reproduction and Embryology. Safe ART services during the third phase of the COVID-19 pandemic. Available from: https://www. eshre.eu/Home/COVID19WG. Accessed 14 Oct 2020.

38. European Society of Human Reproduction and Embryology. ESHRE guidance on recommencing ART treatments. Available from: https://www.eshre.eu/-/media/ sitecore-files/Guidelines/COVID19/ESHRE-Guidanceon-Recommencing-ART-treatments_update-04052020. pdf. Accessed 3 Dec 2020.

39. American Society for Reproductive Medicine. Patient management and clinical recommendations during the Coronavirus (COVID-19) pandemic. Update \#4 (May 11, 2020 through June 8, 2020). Available from: https:// www.asrm.org/globalassets/asrm/asrm-content/newsand-publications/covid-19/covidtaskforceupdate4.pdf. Accessed 3 Dec 2020.

40. The Association of Reproductive and Clinical Scientists, British Fertility Society. Best practice guidelines for reintroduction of routine fertility treatments during the COVID-19 pandemic. Available from: https://www.britishfertilitysociety.org.uk/wpcontent/uploads/2020/05/ARCS-BFS-COVID-19guideline-v1.1-1.pdf. Accessed 3 Dec 2020.

41. The Fertility Society of Australia. Statement of the COVID-19 FSA Response Committee (19 March 2020). Available from: https://www.fertilitysociety.com.au/wpcontent/uploads/20200319-COVID-19-Statement-FSA-
Response-Committee.pdf. Accessed 3 Dec 2020.

42. The Fertility Society of Australia. Updated Statement of the FSA COVID-19 Response Committee. Available from: https://www.fertilitysociety.com.au/home/fsa-statementcovid-19/. Accessed 3 Dec 2020.

43. Vaiarelli A, Bulletti C, Cimadomo D, et al. COVID-19 and ART: the view of the Italian Society of Fertility and Sterility and Reproductive Medicine. Reprod Biomed Online 2020;40:755-9.

44. La Marca A, Niederberger C, Pellicer A, Nelson SM. COVID-19: lessons from the Italian reproductive medical experience. Fertil Steril 2020;113:920-2.

45. Fabregues F, Peñarrubia J. Assisted reproduction and thromboembolic risk in the COVID-19 pandemic. Reprod Biomed Online 2020;41:361-4.

46. Monteleone PA, Nakano M, Lazar V, Gomes AP, de H Martin, Bonetti TC. A review of initial data on pregnancy during the COVID-19 outbreak: implications for assisted reproductive treatments. JBRA Assist Reprod 2020;24:21925.

47. Alviggi C, Esteves SC, Orvieto R, et al. COVID-19 and assisted reproductive technology services: repercussions for patients and proposal for individualized clinical management. Reprod Biol Endocrinol 2020;18:45.

48. Esteves SC, Lombardo F, Garrido N, et al. SARS-CoV-2 pandemic and repercussions for male infertility patients: a proposal for the individualized provision of andrological services. Andrology 2021;9:10-8.

49. Arav A. A recommendation for IVF lab practice in light of the current COVID-19 pandemic. J Assist Reprod Genet 2020;37:1543.

50. Kashi AH. COVID-19 and semen: an unanswered area of research. Urol J 2020;17:328.

51. Pascolo L, Zito G, Zupin L, et al. Renin angiotensin system, COVID-19 and male fertility: any risk for conceiving? Microorganisms 2020;8:1492.

52. Geber S, Prates N, Sampaio M, Valle M, Meseguer M. COVID-19 should be a novel indication for fertility preservation. JBRA Assist Reprod 2020;24:233-4.

53. Souza M, Nakagawa H, Taitson PF, Cordts EB, Antunes RA. Management of ART and COVID-19: infertility in times of pandemic. What now? JBRA Assist Reprod 2020;24:2312.

54. Juan J, Gil MM, Rong Z, Zhang Y, Yang H, Poon LC. Effects of coronavirus disease 2019 (COVID-19) on maternal, perinatal and neonatal outcomes: a systematic review. Ultrasound Obstet Gynecol 2020;56:15-27.

55. Elshafeey F, Magdi R, Hindi N, et al. A systematic scoping review of COVID-19 during pregnancy and childbirth. Int J Gynaecol Obstet 2020;150:47-52.

56. Dashraath P, Wong JL, Lim MX, et al. Coronavirus disease 2019 (COVID-19) pandemic and pregnancy. Am J Obstet Gynecol 2020;222:521-31.

57. Yang Z, Wang M, Zhu Z, Liu Y. Coronavirus disease 2019 (COVID-19) and pregnancy: a systematic review. J Matern Fetal Neonatal Med 2020 Apr 30. Epub ahead of print.

58. Allotey J, Stallings E, Bonet M, et al. Clinical manifestations, risk factors, and maternal and perinatal outcomes of coronavirus disease 2019 in pregnancy: living systematic review and meta-analysis. BMJ 2020;370:m3320.

59. Rodriguez-Wallberg KA, Wikander I. A global recommendation for restrictive provision of fertility treatments during the COVID-19 pandemic. Acta Obstet Gynecol Scand 2020;99:569-70. 